\title{
Gut lavage IgG and interleukin 1 receptor antagonist:interleukin $1 \beta$ ratio as markers of intestinal inflammation in children with inflammatory bowel disease
}

\author{
R Troncone, N Caputo, A Campanozzi, M Cucciardi, V Esposito, R Russo, B De Vizia,
} L Greco, S Cucchiara

\begin{abstract}
Background-Whole gut lavage is currently used as preparation before radiological or endoscopic examination of the large bowel.

Aim-To validate the gut lavage technique for the assessment of mucosal inflammation, by measuring intestinal IgG and interleukin $1 \beta(I L-1 \beta)$ in the fluid obtained.

Patients-Sixteen children with Crohn's disease (CD), 14 with ulcerative colitis (UC), and 22 age matched controls.

Methods-Isotonic, non-absorbable polyethylene glycol based lavage solution was given orally or by nasogastric tube. Clear fluid was collected, filtered, and treated with protease inhibitors. IgG, IL-1 $\beta$ and IL-1 receptor antagonist (IL-1-ra) were measured by sandwich enzyme linked immunosorbent assay (ELISA).

Results-In patients with UC and CD, IgG and IL-1 $\beta$ levels were significantly $(p<0.001)$ higher than in controls. A positive correlation $(p<0.05)$ was found with disease activity scores. IL-1-ra levels were not significantly different in UC and $C D$, when compared with controls, but the IL-1-ra:IL-1 $\beta$ ratio was significantly ( $p<$ $0.01)$ lower in patients with $U C$ and $C D$, and negatively $(p<0.001)$ correlated with IgG levels in lavage fluid.

Conclusions-Gut lavage fluid IgG and IL-1 $\beta$ levels and IL-1-ra:IL-1 $\beta$ ratio may provide objective discrimination between active and inactive disease in children with inflammatory bowel disease.

(Gut 1997; 41: 60-65)
\end{abstract}

Department of

Paediatrics,

University Federico II, Naples, Italy

Troncone

N Caputo

A Campanozzi

M Cucciardi

V Esposito

R Russo

B De Vizia

L Greco

S Cucchiara

Correspondence to: Dr Riccardo Troncone, Department of Paediatrics, via S Pansini 5, I-80131 Naples, Italy.

Accepted for publication 28 January 1997 disease (CD) are separate diseases of unknown and probably different aetiologies, they share a dysregulated mucosal immune response. Investigation of local immunity is not only relevant for understanding the pathogenic mechanisms underlying these conditions, it is also important for clinical management of the patients. As the mucosal immune system is largely independent of the systemic immune system, for clinical purposes, measurement of antibodies and cytokines in the serum, or counts of circulating cells, does not provide reliable information on the process taking place at the mucosal level. However, access to intestinal secretions and tissue is often difficult, requiring the use of invasive techniques; this raises practical and ethical problems, particularly in children.

In recent years a non-invasive gut lavage technique has been described to measure antibody content in intestinal secretions. ${ }^{1} \mathrm{~A}$ peroral whole gut lavage with non-absorbable polyethylene glycol based solution has gained success in clinical practice for cleansing the bowel prior to barium enema, colonoscopy, or colonic surgery. O'Mahony et al validated such a method as a non-invasive means of studying humoral immunity in gastrointestinal disease. ${ }^{2}$ Since then, a series of studies in adults, from the same laboratory, have shown that whole gut lavage fluid, adequately processed, can readily be used for biochemical, immunochemical, and cellular studies, to assess intestinal immunity, ${ }^{23}$ inflammation, ${ }^{45}$ and gut losses of protein ${ }^{6}$ and blood. ${ }^{7}$

Whole gut lavage has been safely used in paediatric practice, not only for bowel cleansing prior to investigation or surgery, ${ }^{8}$ but also to treat constipation. ${ }^{9}$ This technique has also been used to investigate intestinal immunity in children from an area at high risk for parasite infections and malnutrition, ${ }^{10}$ and, more recently, to assess intestinal inflammation in children affected by cystic fibrosis. ${ }^{11}$ In this paper we report the results of investigations performed on whole gut lavage fluid from children undergoing colonoscopy, either as first diagnostic procedure because of the clinical suspicion of inflammatory bowel disease (IBD), or during follow up in patients in whom the diagnosis of IBD was already established. To assess local inflammation, total IgG and IL-1 $\beta$, and its naturally produced inhibitor, IL-1 receptor antagonist, have been measured in the lavage fluid, and their levels correlated with disease activity scores.

\section{Methods}

SUBJECTS

Thirty patients with IBD were studied: 16 with CD ( 8 male and 8 female; median age 9.9 years, range $3 \cdot 2-17 \cdot 9)$ and 14 with UC (7 male 
TABLE 1 Extension, severity, disease duration, and treatment in children with Crohn's disease enrolled

\begin{tabular}{|c|c|c|c|c|c|c|}
\hline Case & Sex & $\begin{array}{l}\text { Age } \\
(y)\end{array}$ & Localisation & Endoscopy & $\begin{array}{l}\text { Duration } \\
\text { (y) }\end{array}$ & Treatment \\
\hline 1 & F & $6 \cdot 7$ & R-DC-TC-I & Moderate & $0 \cdot 2$ & None \\
\hline 2 & $\mathrm{~F}$ & $13 \cdot 6$ & S-DC-I & Moderate & $4 \cdot 0$ & Elemental diet \\
\hline 3 & $\mathbf{F}$ & $14 \cdot 4$ & I & Mild & $1 \cdot 3$ & None \\
\hline 4 & $\mathrm{~F}$ & $7 \cdot 0$ & I & Moderate & $1 \cdot 0$ & Pentasa \\
\hline 5 & $\mathbf{M}$ & $7 \cdot 6$ & I & Mild & $2 \cdot 0$ & None \\
\hline 6 & $\mathrm{~F}$ & $3 \cdot 2$ & $\mathrm{AC}$ & Moderate & $2 \cdot 0$ & None \\
\hline 7 & M & $13 \cdot 2$ & I & Mild & $1 \cdot 0$ & None \\
\hline 8 & M & $13 \cdot 8$ & I & Moderate & $7 \cdot 0$ & Pentasa \\
\hline 9 & $\mathbf{M}$ & $17 \cdot 9$ & I & Moderate & $4 \cdot 0$ & Pentasa \\
\hline 10 & M & $9 \cdot 5$ & R-S-DC-TC-AC-I & Moderate & $1 \cdot 0$ & None \\
\hline 11 & $\mathrm{~F}$ & $12 \cdot 0$ & R-S-DC-TC-AC-I & Severe & 0.8 & None \\
\hline 12 & $\mathbf{M}$ & $13 \cdot 7$ & AC-DC-TC & Moderate & $0 \cdot 4$ & None \\
\hline 13 & $\mathrm{~F}$ & $12 \cdot 0$ & C & Mild & $0 \cdot 8$ & Elemental diet \\
\hline 14 & M & $13 \cdot 6$ & I-TC-DC & Moderate & 0.8 & Asacol \\
\hline 15 & $\mathbf{M}$ & $9 \cdot 4$ & I & Moderate & $0 \cdot 1$ & None \\
\hline 16 & $\mathrm{~F}$ & $14 \cdot 3$ & I & Mild & 0.4 & Elemental diet \\
\hline
\end{tabular}

Localisation: $\mathrm{R}$, rectum; S, sigmoid colon; AC, ascending colon; DC, descending colon; TC, transverse colon; C, caecum; I, ileum.

Endoscopy: mild (hyperaemia, friability, oedema); moderate (isolated erosions); severe (diffuse ulcerations, spontaneous bleeding).

and 7 female; median age 9.6 years, range $2 \cdot 1-17 \cdot 5)$. In all patients the diagnosis of CD or UC was established using conventional clinical, histological, and endoscopic criteria. Clinical details including disease duration, localisation, severity, and medical treatment at the moment of gut lavage are given in tables 1 and 2. Four CD patients and one UC patient were studied on two separate occasions. The control group contained 22 age matched subjects; the diagnosis of IBD, and in general the presence of inflammation, was excluded in all of them by endoscopic and histological criteria. Final diagnosis was: constipation ( $\mathrm{n}=$ $6)$, recurrent abdominal pain $(n=6)$, intestinal polyp $(n=2)$, and irritable bowel disease $(n=8)$.

All patients were clinically assessed by two of us, and a disease activity score index was calculated on the basis of the Pediatric Crohn Disease Activity Index ${ }^{12}$ and Powell Tuck Index, ${ }^{13}$ for $\mathrm{CD}$ and UC patients, respectively. The latter includes subjective reporting of the degree of abdominal pain, stool pattern, general well being, presence of extraintestinal manifestations, physical examination findings, haematocrit, ESR, and serum albumin; no endoscopic features are included. In all IBD patients other haematological and biochemical indices including haemoglobin, white cell counts,

TABLE 2 Extension, severity, disease duration, and treatment in children with ulcerative colitis enrolled

\begin{tabular}{rlrllll}
\hline Case & Sex & \multicolumn{1}{c}{$\begin{array}{c}\text { Age } \\
(y)\end{array}$} & Localisation & Endoscopy & $\begin{array}{l}\text { Duration } \\
(y)\end{array}$ & Treatment \\
\hline 1 & M & $15 \cdot 3$ & R-S-DC & Severe & $3 \cdot 0$ & Salazopyrine, azathioprine \\
2 & M & $9 \cdot 6$ & TC-DC-R-S & Severe & $4 \cdot 0$ & None \\
3 & F & $7 \cdot 4$ & R-S-DC-AC & Severe & $1 \cdot 0$ & None \\
4 & F & $10 \cdot 9$ & R-S-DC-TC-AC & Severe & $0 \cdot 3$ & None \\
5 & M & $10 \cdot 7$ & R-S-DC-TC-AC-I & Moderate & $0 \cdot 1$ & None \\
6 & F & $7 \cdot 6$ & R-S-DC & Severe & $0 \cdot 1$ & None \\
7 & F & $2 \cdot 1$ & R-S-DC-TC & Severe & $0 \cdot 1$ & None \\
8 & M & $7 \cdot 8$ & R-S-DC & Mild & $0 \cdot 1$ & None \\
9 & F & $8 \cdot 0$ & AC & Moderate & $2 \cdot 0$ & None \\
10 & F & $6 \cdot 2$ & R-S-DC-TC-AC & Severe & $0 \cdot 5$ & None \\
11 & M & $8 \cdot 7$ & R-S-DC & Mild & $3 \cdot 0$ & None \\
12 & M & $17 \cdot 5$ & R-S-DC & Moderate & $1 \cdot 0$ & Prednisolone, Pentasa \\
13 & M & $10 \cdot 3$ & AC-TC-DC & Severe & $4 \cdot 0$ & Asacol foam, Pentasa \\
14 & M & $10 \cdot 6$ & R-S-DC-TC-AC & Severe & $3 \cdot 0$ & Pentasa \\
& & & & & & \\
\hline
\end{tabular}

Localisation: $\mathrm{R}$, rectum; S, sigmoid colon; AC, ascending colon; DC, descending colon; TC,

transverse colon; C, caecum; I, ileum. single ulcerations); severe (gross diffuse ulcerations, bleeding)
C reactive protein, and serum immunoglobulins were also recorded on the day of lavage.

LAVAGE PROTOCOL AND PROCESSING OF LAVAGE FLUID

The lavage fluid used was a non-absorbable polyethylene glycol (PEG) based electrolyte lavage solution (SELG, Promefarm, Milan, Italy). The lavage solution contained $58.32 \mathrm{~g}$ PEG 4000, 5.69 g sodium sulphate anydrite, $1.69 \mathrm{~g}$ sodium bicarbonate, $1.46 \mathrm{~g}$ sodium chloride, and $0.74 \mathrm{~g}$ potassium chloride, made up to one litre. After an overnight fast this solution was given by mouth, or by nasogastric tube, at a rate of $30 \mathrm{ml} / \mathrm{kg} /$ hour. When material passed per rectum became liquid, clear, and free of faecal material, specimens were collected, filtered, and treated with protease inhibitors. To $5 \mathrm{ml}$ of such fluid were added: $500 \mu \mathrm{l}$ soya bean trypsin inhibitor $(1 \mathrm{mg} / \mathrm{ml}$ in PBS $0.15 \mathrm{M}, \mathrm{pH} 7 \cdot 2) ; 280 \mu$ I EDTA $(0.3 \mathrm{M}$, $\mathrm{pH} 8) ; 120 \mu \mathrm{l}$ phenylmethylsulphonil fluoride (0.1 M in $95 \%$ ethanol); $60 \mu \mathrm{l} \mathrm{NaN} \mathrm{N}_{3}(2 \mathrm{~g} / 100$ $\mathrm{ml}$ ); and $300 \mu \mathrm{l}$ newborn calf serum. All specimens were aliquoted and stored at $-80^{\circ} \mathrm{C}$. The procedure was performed in the paediatric inpatient's ward and supervised by one of us.

\section{IMMUNOASSAYS}

\section{IgG}

IgG was measured by enzyme linked immunosorbent assay (ELISA). Assays were performed in 96-well microtitre ELISA plates (Sero-Wel, Sterilin). Wells were coated with affinity purified antihuman IgG in $0.05 \mathrm{M}$ carbonate buffer $\mathrm{pH} 9 \cdot 6$, and incubated overnight at $4^{\circ} \mathrm{C}$. Wells were saturated with bovine serum (Sigma) $10 \%$ in phosphate buffered saline $0.1 \mathrm{M}$ pH $7 \cdot 2$ (PBS), and incubated for one hour at $37^{\circ} \mathrm{C}$. After washing with PBS-Tween 20,0.05\%, serial twofold dilutions ranging from 2500 to $20 \mathrm{ng} / \mathrm{ml}$ of a human IgG standard (Sigma), and serial dilutions of treated lavage samples (initial dilutions $1 / 5$ ), were added to the coated wells. Plates were incubated for 1 hour at $37^{\circ} \mathrm{C}$ and washed. Peroxidase conjugated goat antihuman IgG (ICN Immunobiologicals), diluted in saline with $10 \%$ fetal calf serum, was added and plates were incubated for 1 hour at $37^{\circ} \mathrm{C}$ After washing, $o$-phenylenediamine $(1 \mathrm{mg} / \mathrm{ml})$ in citrate buffer $1 \mathrm{M}$ pH 5 was added as substrate. Plates were read at OD $450 \mathrm{~nm}$ in an ELISA reader. A standard curve was constructed; the IgG content of any given sample was determined by taking the mean IgG content of the sample dilutions whose optical density fell within the range of the standard curve. The within run and the between run coefficients of variation were $6 \cdot 8 \%$ and $9 \cdot 5 \%$, respectively.

Interleukin $1 \beta$ and interleukin 1 receptor antagonist Interleukin $1 \beta$ (IL-1 $\beta$ ) and interleukin 1 receptor antagonist (IL-1-ra) were measured by sandwich ELISA using commercial kits (R\&D 
Systems, Minneapolis, USA). The detection limits were $0.3 \mathrm{pg} / \mathrm{ml}$ and $6.5 \mathrm{pg} / \mathrm{ml}$ for IL-1 $\beta$ and IL-1-ra, respectively. The within run and the between run coefficients of variation were $7 \cdot 8 \%$ and $12 \cdot 1 \%$, and $5 \cdot 8 \%$ and $9 \cdot 6 \%$, for IL$1 \beta$ and IL-1-ra, respectively. Gut lavage fluid was tested undiluted and diluted $1 / 10$, for IL$1 \beta$ and IL-1-ra measurement, respectively. The ELISA measurements were performed using unthawed samples.

\section{STATISTICS}

Raw data have been presented as median and interquartile intervals. Because of the high kurtosis and skewness, data were normalised by $\log$ transformation, and parametric tests (Student's $t$ test) were then applied. One way analysis of variance was performed for a three group comparison. Correlations were calculated by Pearson correlation coefficients. The statistical analysis was carried out using SSPS software. Differences were considered statistically significant for $\mathrm{p}<0 \cdot 05$.

ETHICS

Informed written consent was obtained from all patients or a parent/guardian where appropiate. The study was approved by the Ethical Committee of the University Federico II of Naples.

\section{Results}

TECHNIQUE VALIDATION

The technique was well tolerated by most patients; in 5/57 lavages children complained of bloating and nausea, complicated by vomiting in two cases. These problems quickly settled by slowing the rate of administration of the gut lavage solution. Data obtained from testing serial lavage specimens showed that once the specimens became clear and free of faecal material, a steady state was reached, with little variation in IgG content.

IgG

In the comparison between groups only one gut lavage specimen (the first in the case of repeated lavages) was considered for analysis. IgG was detectable in all the specimens, including those from 22 individuals classified

TABLE 3 IgG, IL-1,$I L-1-$ ra and IL-1-ra:IL-1 $\beta$ in whole gut lavage fluid of children with IBD and controls

\begin{tabular}{|c|c|c|c|c|c|c|c|c|}
\hline \multirow[b]{2}{*}{ Variable } & \multirow{2}{*}{$\begin{array}{l}\text { Group } 1 \\
\text { Crohn's } \\
\text { disease }\end{array}$} & \multirow{2}{*}{$\begin{array}{l}\text { Group 2 } \\
\text { Ulcerative } \\
\text { colitis }\end{array}$} & \multirow{2}{*}{$\begin{array}{l}\text { Group } 3 \\
\text { Controls }^{\star}\end{array}$} & \multicolumn{3}{|l|}{$p^{\star \star}$} & \multicolumn{2}{|c|}{$A N O V A$} \\
\hline & & & & $1 \times 2$ & $1 \mathrm{v} 3$ & $2 \times 3$ & $F$ & $p$ \\
\hline IgG & $\begin{array}{l}0.92(0.82) \\
(n=16)\end{array}$ & $\begin{array}{l}1.32(0.51) \\
(n=14)\end{array}$ & $\begin{array}{l}0.09(0.39) \\
(\mathrm{n}=22)\end{array}$ & $0 \cdot 11$ & 0.001 & 0.001 & $18 \cdot 01$ & 0.001 \\
\hline IL $-1 \beta$ & $\begin{array}{l}1 \cdot 66(0.67) \\
(n=15)\end{array}$ & $\begin{array}{l}2 \cdot 06(0.57) \\
(n=14)\end{array}$ & $\begin{array}{l}0 \cdot 87(0 \cdot 61) \\
(n=20)\end{array}$ & $0 \cdot 10$ & 0.001 & 0.001 & $16 \cdot 03$ & 0.001 \\
\hline IL-1-ra & $\begin{array}{l}2 \cdot 68(1 \cdot 63) \\
(n=16)\end{array}$ & $\begin{array}{l}3.59(1.07) \\
(n=14)\end{array}$ & $\begin{array}{l}3.51(0 \cdot 47) \\
(\mathrm{n}=18)\end{array}$ & 0.08 & 0.065 & 0.809 & $3 \cdot 10$ & 0.055 \\
\hline IL-1-ra:IL-1 $\beta$ & $\begin{array}{l}1 \cdot 19(1 \cdot 88) \\
(n=15)\end{array}$ & $\begin{array}{l}1 \cdot 53(1 \cdot 19) \\
(n=14)\end{array}$ & $\begin{array}{l}2 \cdot 67(0.67) \\
(n=18)\end{array}$ & 0.57 & .0 .010 & 0.005 & $5 \cdot 82$ & 0.006 \\
\hline
\end{tabular}

*Values expressed as mean (SD) of log values.

$\star \star \mathrm{p}$ from unpaired Student's $t$ test between two groups and from one way analysis of variance (ANOVA).

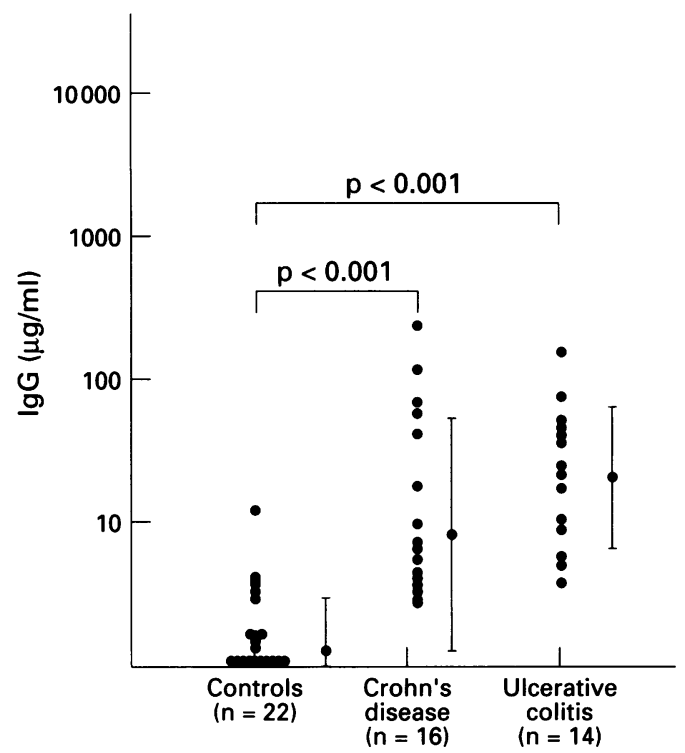

Figure 1: IgG levels in whole gut lavage fluid from patients with inflammatory bowel disease and controls. Bars indicate mean and standard deviations, calculated after data were normalised by log transformation.

as normal. In controls, the median and interquartile interval for $\operatorname{IgG}$ were 1.35 and $0.58-1.85 \mu \mathrm{g} / \mathrm{ml}$, respectively. In CD patients (median 5.8; interquartile interval $1 \cdot 8-54.8$ $\mu \mathrm{g} / \mathrm{ml}$ ) and in UC patients (median 23.5; interquartile interval $8 \cdot 4-48 \cdot 8 \mu \mathrm{g} / \mathrm{ml}$ ) IgG levels were significantly higher $(p<0 \cdot 001)$ than in controls. An analysis of variance confirmed significant differences between the groups (table 3). Abnormally high concentrations of IgG $(>1.8 \mu \mathrm{g} / \mathrm{ml})$ were present in all UC patients and in $75 \%(12 / 16)$ of CD patients (fig 1).

All gut lavage specimens, and also those obtained on further occasions from the same patients, were considered when the correlation between IgG levels and disease activity scores was analysed. IgG levels in gut lavage fluid from IBD patients were positively correlated with disease activity scores both in CD $(r=$ $0.56 ; \mathrm{p}<0.01)$ and in UC $(r=0.55 ; \mathrm{p}<0.05)$ (fig 2).

IL-1 $\beta$ AND IL-1-ra

In the comparison between groups only one gut lavage specimen (the first in the case of repeated lavages) was considered for analysis. IL-1 $\beta$ was measured in $20 / 22$ and $29 / 30$ lavage fluid specimens from controls and IBD patients, respectively. As shown in fig 3, both in UC patients (median 81 ; interquartile interval 9-154 pg/ml) and CD patients (median 101.5 ; interquartile interval $52-296.5 \mathrm{pg} / \mathrm{ml}$ ), these levels were significantly higher $(p<0.001)$ than in controls (median 6.5; interquartile interval $3-21.3 \mathrm{pg} / \mathrm{ml}$ ). An analysis of variance confirmed significant differences between the groups (table 3). A statistically significant correlation was found between concentrations of IL-1 $\beta(r=0.72 ; p<0.001)$ and IgG.

IL-1-ra levels were not significantly higher in UC patients (median 6500; interquartile interval $4775-13070 \mathrm{pg} / \mathrm{ml}$ ), and in $\mathrm{CD}$ 

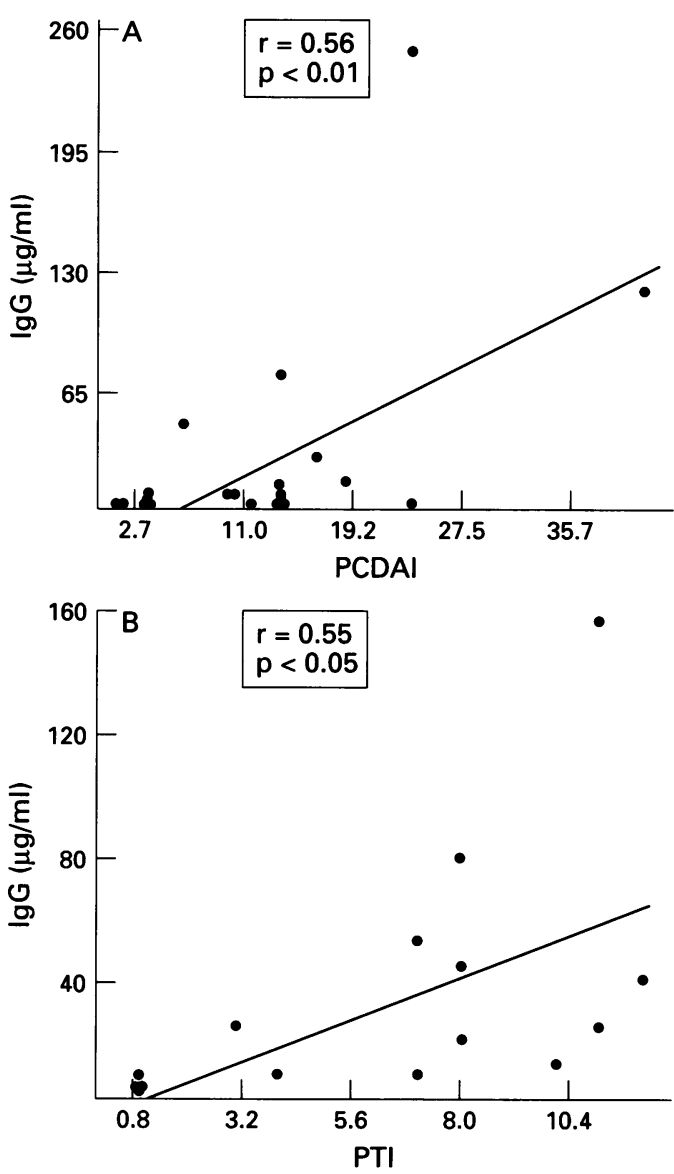

Figure 2: Concentrations of IgG measured in 20 gut lavage fluid specimens from $C D$ patients, and 15 gut lavage fluid specimens from UC patients, plotted against Pediatric Crohn Disease Activity Index (PCDAI) $(A)$, and Powell Tuck Index (PTI) (B).

patients (median 3050; interquartile interval $188-5685 \mathrm{pg} / \mathrm{ml}$ ), when compared with controls (median 4350; interquartile interval $1137-7274 \mathrm{pg} / \mathrm{ml})$. The IL-1-ra:IL-1 $\beta$ ratio was, both in UC and in $C D$ patients, significantly $(p<0.01)$ lower than in controls (fig 4). No correlation was observed between

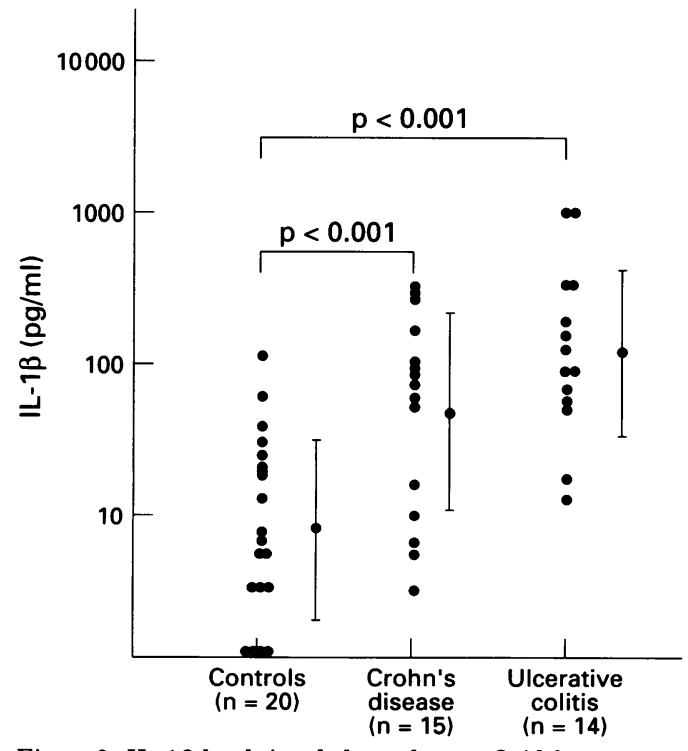

Figure 3: IL-1 $\beta$ levels in whole gut lavage fluid from patients with inflammatory bowel disease and controls. Bars indicate mean and standard deviations, calculated after data were normalised by log transformation.

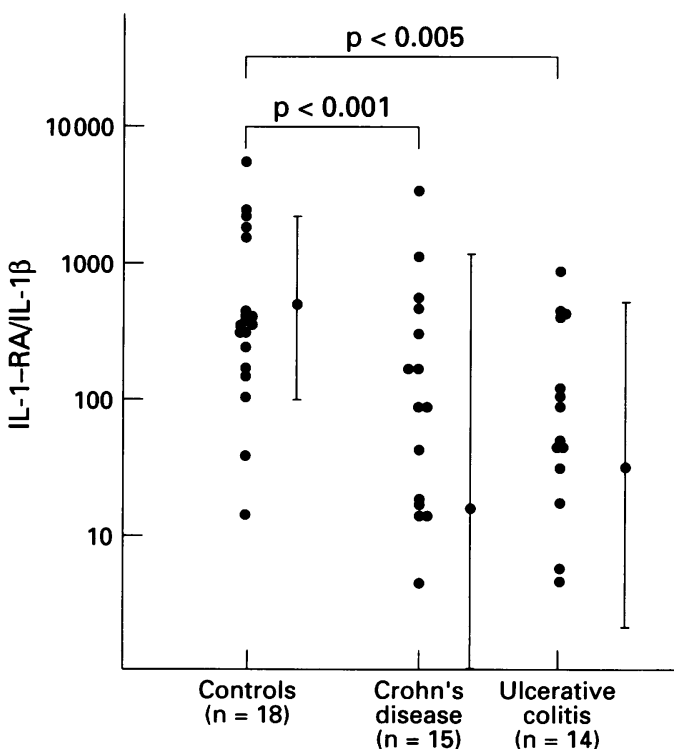

Figure 4: IL-1-ra:IL-1 $\beta$ ratios in whole gut lavage fluid from patients with inflammatory bowel disease and controls. Bars indicate mean and standard deviations, calculated after data were normalised by log transformation.

disease severity and the levels of IL-1-ra or the IL-1-ra:IL- $1 \beta$ ratio. In contrast, a significant negative correlation was observed between the IL-1-ra:IL-1 $\beta$ ratio and IgG levels $(r=-0 \cdot 49$; $\mathrm{p}<0 \cdot 001$ ).

\section{Discussion}

The gut lavage technique used in this study has proved to be a safe, non-invasive, well tolerated procedure in children. Previous published studies, $^{2}$ and pilot observations in our laboratory, have shown that, after gut cleansing is complete, the clear fluid passed per rectum is essentially a whole gut perfusate, which, appropriately processed, can be usefully used to assess intestinal immunity. Immunoglobulins, antibodies and cytokines can also be detected in saline extracts of faeces, but the significant loss of immunoreactive immunoglobulins and specific antibody activity, particularly in subjects with no active gut inflammation, render the results difficult to interpret, and in general unreliable. ${ }^{14}$

In the present study we have measured higher concentrations of IgG in gut lavage fluid of children with IBD when compared with controls. The latter values in our series are not dissimilar to those recently published by Croft et al. ${ }^{11}$ The finding of higher IgG concentrations in gut lavage fluid of IBD children confirms previous observations in adults. ${ }^{45}$ $\mathrm{IgG}$ is derived from the expanded IgG producing cell population noted in the diseased mucosa, ${ }^{15}$ and probably also from plasma leakage, as suggested by the concurrent presence of other plasma proteins showed by Choudari et al. ${ }^{5}$ We have also confirmed in our paediatric cohort that IgG concentrations in lavage fluid correlate with disease activity scores, as defined by the Crohn Disease Activity Index and Powell Tuck Index. The correlation is less than has been obtained in adults; this could reflect the lower number of observations, as well as difficulties in carrying 
out the global scoring system in children. Higher IgG levels found in UC are accounted for by the higher number of UC patients with high activity scores, when compared with CD patients; it is also possible that immunological differences do exist between UC and CD. Furthermore, the site of inflammation - small bowel or colon - is likely to influence the results. These aspects are currently being evaluated.

In IBD patients, as in other inflammatory conditions, cytokines play a key role in pathogenesis. We have investigated their clinical relevance as objective markers of disease activity. Studies based on serum and also faecal measurement of cytokines have yielded conflicting results. Serum levels may be indirect indicators of the degree of tissue inflammation, and faecal cytokines may undergo substantial variation before appearance in faeces; caution must therefore be applied in the interpretation of results. We have used ELISA to measure some proinflammatory cytokines in gut lavage fluid. IL-1 $\beta$ was detected in virtually all specimens from both $\mathrm{CD}$ and UC children; it was also detected in a high proportion of control specimens, but levels were significantly higher in IBD patients. Enhanced IL-1 $\beta$ production has been reported in gut tissue of an animal model of intestinal inflammation, ${ }^{16}$ in the mucosa, ${ }^{17}$ and in cell preparations isolated from the intestine of patients with active $\mathrm{IBD}^{18}$; IL- $1 \beta$ is predominantly synthesised by lamina propria macrophages and only marginally by epithelial cells. ${ }^{19}$ IL-1 $\beta$ gut lavage levels significantly correlated with IgG levels, a reliable marker of disease activity.

The biological activity of proinflammatory cytokines is regulated at several levels: transcription, processing, release, and binding to soluble cytokine receptors in the extracellular milieu. In the case of IL-1 $\beta$, a further downregulating mechanism is provided by the production and secretion of a naturally occurring 22-kilodalton protein, IL-1-ra. ${ }^{20} \mathrm{IL}-$ 1 -ra is secreted by the same cells that produce IL- $1 \beta$, and acts as a pure antagonist to IL- $1 \beta$, binding to the IL-1 receptor located on target cells with no known agonist effects. ${ }^{21}$ The balance between IL-1 $\beta$ and its natural antagonist IL-1-ra is a better indicator of the number of active proinflammatory molecules, and ultimately a more sensitive indicator of disease severity. In IBD tissue IL-1-ra is reported to be increased, showing a significantly greater elevation in $\mathrm{UC}^{22}{ }^{23}$; this confirms its possible role in the hosts's homoeostatic mechanism for downregulating inflammatory processes. In our series we could not confirm high IL-1-ra levels in IBD patients, but in both UC and CD patients the IL-1 ra:IL-1 ratio was significantly lower. It has been reported that such a phenomenon is specific for IBD, not having been noted in patients with self-limiting colitis. ${ }^{22}$ For this reason it has been advocated as the critical factor, probably genetically determined, ${ }^{24}$ predisposing the individual to chronic inflammation.
In conclusion, our work shows that the gut lavage technique is well tolerated and acceptable in paediatric clinical practice. As the method is used for bowel cleansing in many clinical situations (endoscopy, radiology, surgery), lavage fluid may become immediately available for immunochemical assays. In particular, the results presented here clearly show that IgG and IL-1 $\beta$ levels, as well as the IL-1 $\beta$ :IL-1-ra ratio may provide in IBD children an objective and quantitative method for evaluation of the degree of mucosal inflammation, and a method to follow accurately the evolution of the disease. We also believe that the gut lavage technique, by measurement of the markers discussed in this study, and also other markers (for example, elastase and eosinophil cationic protein), has the potential to provide important information in the differential diagnosis of colitis, particularly in infancy and childhood, where tests able to identify the infectious or allergic nature of gut inflammatory processes would have a strong clinical impact.

The authors are indebted to F S Di Giovine (Dept of Molecular Medicine, University of Sheffield) for helpful discussion. This redicine, University of Shefield) for hrom the Italian Ministry of University and Scientific and Technological Research $(60 \%$ funds).

1 Gaspari MM, Brennan PT, Solomon SM, Elson CO. A method of obtaining, processing, and analyzing human method of obtaining, processing, and analyzing human Methods 1988; 110: 85-91.

2 O'Mahony S, Barton JR, Crichton S, Ferguson A. Appraisal of gut lavage in the study of intestinal humoral immunity. Gut 1990; 31: 1341-4.

3 O'Mahony S, Arranz E, Barton JR, Ferguson A. Dissociation between systemic and mucosal humoral immune responses in coeliac disease. Gut 1991; 32: 29-35.

4 O'Mahony S, Choudari CP, Barton JR, Walker S, Ferguson A. Gut lavage fluid proteins as markers of activity of inflammatory bowel disease. Scand $\mathcal{f}$ Gastroenterol 1991; 26: $940-4$.

5 Choudari CP, O'Mahony S, Brydon G, Mwantembe O, Ferguson A. Gut lavage fluid protein concentrations: objective measures of disease activity in inflammatory objective measures of disease activity in inflamm
bowel disease. Gastroenterology 1993; 104: 1064-71.

6 Brydon WG, Choudari CP, Ferguson A. Relative specificity for active inflammatory bowel disease of plasma-derived for active inflammatory bowel disease of plasma-derived proteins in gut lava

7 Brydon WG, Ferguson A. Haemoglobin in gut lavage fluid as a measure of gastro-intestinal blood loss. Lancet 1993; 340: 1381-2.

8 Tolia V, Fleming S, Dubois RS. Use of golytely in children and adolescents. $\mathcal{F}$ Pediatr Gastroenterol Nutr 1984; 3: 468-70.

9 Ingebo KB, Heyman MB. Polyethyleneglycol-electrolyte solution for intestinal clearance in children with refractory encopresis. A safe and effective therapeutic program. Am $\mathcal{F}$ Dis Child 1988; 142: 340-2.

10 Hodges M, Kingstone K, Brydon WG, Sallam J, Ferguson A. Use of whole gut lavage to measure intestinal immunity in healthy Sierra Leonean children. $\mathcal{F}$ Pediatr Gastroenterol in healthy Sierra Leon

11 Croft NM, Marshall TG, Ferguson A. Gut inflammation in children with cystic fibrosis on high-dose enzyme children with cystic fibrosis on high-

12 Hyams J, Ferry GD, Mandel FS, Gryboski JD, Kibort MP, et al. Development and validation of a Pediatric Crohn's et al. Development and validation of a Pediatric Crohn's 12: 439-47.

13 Powell-Tuck J, Bown RL, Lennard-Jones JE. A comparison of oral prednisolone given as single or multiple daily doses for active proctocolitis. Scand $\mathcal{F}$ Gastroenterol 1978; 13: 833-7.

14 Ferguson A, Humphreys K, Croft N. Technical report: results of immunological tests on faecal extracts are likely to be extremely misleading. Clin Exp Immunol 1995; 99: $70-5$.

15 Baklien K, Brandtzaeg P. Immunohistochemical characterisation of local immunoglobulin formation in Crohn's disease of the ileum. Scand 7 Gastroenterol 1976; 11: 447-57.

16 Cominelli F, Nast CC, Clark BD, Schindler R, Llerena R, Eysselein VE, et al. Interleukin 1 (IL-1) gene expression, synthesis, and effect of specific IL-1 receptor blockade in rabbit immune complex colitis. f Clin Invest 1990; 86: 972-80. 
17 Ligumsky M, Simon PL, Karmeli F, Rachmilewitz D. Role of interleukin 1 in inflammatory bowel disease - enhanced production during active disease. Gut 1990; 31: 686-9.

18 Mahida YR, Wu K, Jewell DP. Enhanced production of interleukin 1-beta by mononuclear cells isolated from mucosa with active ulcerative colitis of Crohn's disease. Gut 1989; 30: 835-8.

19 Youngman KR, Simon PL, West GA, Cominelli F, Rachmilewitz D, Klein JS, et al. Localization of intestinal interleukin 1 activity and protein and gene expression to lamina propria cells. Gastroenterology 1993; 104: 749-58.

20 Hannum CH, Wilcox CJ, Arend WP, Joslin FG, Dripps DJ, Heimdal PL, et al. Interleukin-1 receptor antagonist activity of a human interleukin-1 inhibitor. Nature 1990 343: 336 .

21 Dripps DJ, Brandhuber BJ, Thompson RC, Eisenberg SP. Interleukin-1 (IL-1) receptor antagonist binds to the 80
$\mathrm{kDa}$ IL-1 receptor but does not initiate IL-1 signal transduction. F Biol Chem 1991; 266: 10331-6.

22 Casini-Raggi V, Kam L, Chong YJT, Fiocchi C, Pizarro TT, Cominelli F. Mucosal imbalance of IL-1 and IL-1 receptor antagonist in inflammatory bowel disease. A novel mechanism of chronic intestinal inflammation. $\mathcal{F}$ Immunol 1995; 154: 2434-40.

23 Hyams JS, Fitzgerald JE, Wyzga N, Muller R, Treem WR, Justinich CJ, et al. Relationship of interleukin-1 receptor antagonist to mucosal inflammation in inflammatory bowel disease. $\mathcal{F}$ Pediatr Gastroenterol Nutr 1995; 21: 419-25.

24 Mansfield JC, Holden H, Tarlow JK, Di Giovine F, McDowell TL, Wilson AG, et al. Novel genetic association between ulcerative colitis and the antiinflammatory cytokine interleukin-1 receptor antagonist. Gastroenterology 1994; 106: 637-42. 